\title{
FOSTERING CREATIVITY VIA TECHNOSELF ENHANCED LEARNING WITH EMERGING TECHNOLOGIES
}

\author{
L. Jin ${ }^{1}$, K. Forrest ${ }^{2}$ \\ ${ }^{1}$ University of Westminster (UNITED KINGDOM) \\ ${ }^{2}$ Alexandra Palace Trust (UNITED KINGDOM)
}

\begin{abstract}
Creative and collaborative learning has profound implications for all parts of the system we have built up in our societies - not only the education systems but also the social, economic and cultural systems. Technology Enhanced Learning (TEL) research has increasingly focused on emerging technologies, Extended Reality (XR) to improve learner's engagement in enriched multimodal learning environments. This paper recommends technoself pedagogy and investigates $\mathrm{XR}$ for creative learning as a frontier in TEL. In partnership with cultural sectors, we introduce the agile working process in the collaboration with the Alexandra Park and Palace Charitable Trust (AP) and report the project development of two pilot apps based on the proposed methodology. As a result, students as cocreators were engaged in pilot collaborative projects to work on the digital solutions that promote unforgettable stories. The prototypes exploited the latest development of Virtual Reality (VR), Augmented Reality (AR), and game and mobile technology. The pilot pedagogical practice focuses on providing a vibrant collaborative learning environment which fosters innovation and creativity, informed by practice, inspired by TEL research across disciplines. The collaborative learning practices also support cultural sectors to inspire their visitors and to help curators think beyond their current boundaries, providing a new, mixed media and technological approach to raise cultural awareness to wider audiences.
\end{abstract}

Keywords: creative and collaborative learning, technology enhanced learning, Extended Reality (XR).

\section{INTRODUCTION}

The importance of fostering creativity in education has been widely recognized as research has shown creativity helps individuals to respond more productively to the challenges in both personal and professional lives [1]. However, there are challenges for HE to effectively facilitate creative learning and lack of innovative pedagogic practices has been identified as one of the factors [2]. Learning occurs most effectively within a social and practice-focused context in which the construction of knowledge and understanding is facilitated through active participation in learning communities based on open collaboration and communication. Together, creative and collaborative learning has profound implications for nearly all parts of the systems we have built up in our societies including social, economic and cultural systems. In partnership with Alexandra Palace Trust (AP), UK, we aim to improve student engagement through collaborative learning practices with cultural sectors. Nowadays, the cultural sector faces major challenges and stiff competition in how to attract diverse visitors in digital era. It is out of date to present dry history lessons in heritage buildings. In particular, some iconic locations and areas become inaccessible due to on-site building work under national heritage regeneration schemes. To address this problem, we explore alternative intellectual access points to the narratives, enable visitors to connect on a personal level with the place and people, and further maintain the AP spirit of fun and entertainment with educational value.

In this paper, section 2 presents research methodology grounded on our technoself pedagogy and investigates the emerging technology, Extended Reality (XR) for creative learning as a frontier in TEL. Section 3 introduces the applied agile working process in the collaboration and reports the project development of two pilot apps based on the proposed methodology. Preliminary project outcomes and discussions are presented in section 4. As a result, students as co-creators were engaged in a pilot collaborative projects to work on the digital solutions that promote unforgettable stories. The prototypes that were created exploit the immersive qualities of Virtual Reality (VR), Augmented Reality (AR), and game and mobile technology. These included 'Step Back in Time', a mobile VR-based interactive tour of historic BBC television studios that takes visitors back to 1936; and 'Digital 3D Popping up', a mobile interactive AR app showcasing 3D historical TV equipment used in the 1936 BBC studio at Alexandra Palace. Consequently, the collaborative learning practice provides fresh 
perspectives and windows onto inaccessible histories, spaces and collections. It was made up of practical exercises, exhibitions and case studies that elaborate on the potential of digital transformation, increasing relevance and public engagement and impacts and sustainability of symbiotic relationships created. We have introduced transformative innovations in the external collaborative learning projects appropriate for students as co-creators, especially in the use of emerging technologies for fostering creativity. This will help further develop the technoself theory through interdisciplinary pedagogic studies with cultural sectors.

\section{RESEARCH METHODOLOGY}

AP initiatives for the community education programme on 'Teaching the past today to the inquisitive minds of the future', aims to stimulate their visitors' motivation through TEL. In this section, we recommend technoself pedagogy with the application of XR technology in the pilot collaboration that encourages students to apply their subject knowledge to explore novel digital solutions to achieve creative learning and interpretation for the cultural sector.

\subsection{Technoself Pedagogy}

It is essential to acknowledge the complexity of modern society, with emerging technologies (e.g. XR, gaming, mobile and cloud computing) advancing to such an extent that they affect one's self-concept and ways of learning. These result in the formation of the 'technoself' - a new dimension of self, which is driven by the latest scientific and technological innovations. Technoself studies becomes an interdisciplinary research domain to address intractable challenges of human identity in a technological society focusing on the changing nature of relationships between the human and technology [3]. By applying the concept of 'technoself' in education, we established the technoself pedagogy with a focus on an evolving self as a result of the adoption of new learning technology in our previous pedagogic research [4]. The technoself pedagogy aims to shape and reshape the identities of learners and learning communities while facilitating creativity and self-esteem via TEL. Inspired by Davis's Technology Acceptance Model and Bandura's social learning theory [5][6], we generated a deeper understanding of the sociological learning model driven by socio-technical innovations to enhance student engagement and recommend the following technoself enhanced learning framework as shown in Figure 1. The framework highlights the integration of social learning, creative learning, and information curation in order to improve learner's engagement [7]. The 'technoself' plays a major role in how learners perceive learning settings and how they behave in response to different learning situations. It becomes an innovative pedagogic approach to build students' confidence in exploring new experiences or information, and further developing talents and potential in a creative learning environment.

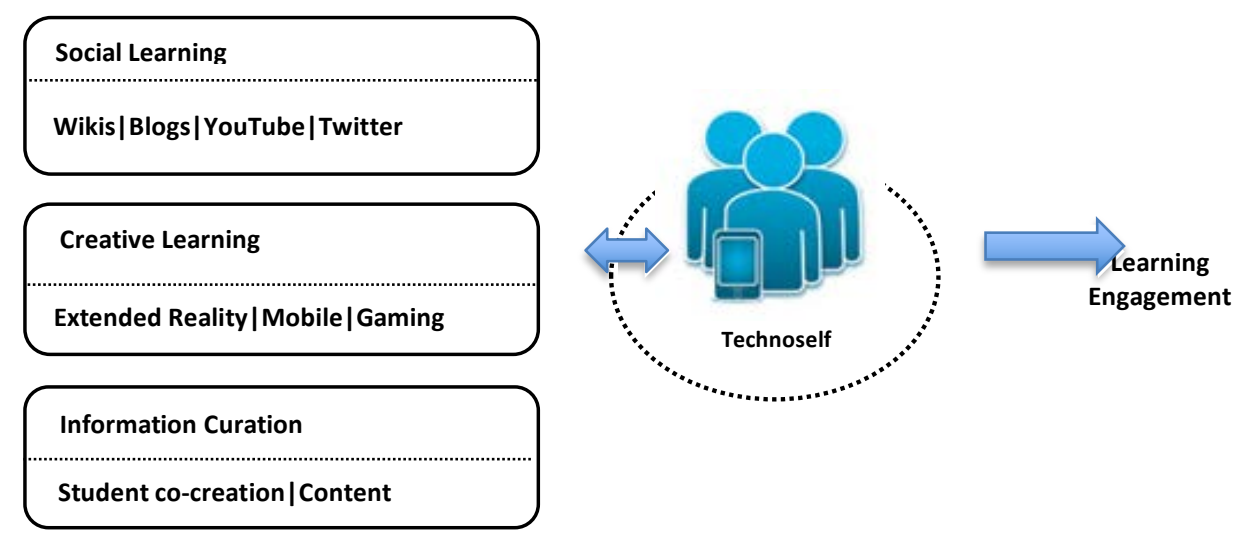

Figure 1. Technoself enhanced learning framework [7].

\subsection{The Frontier in TEL: Extended Reality for Creative Learning}

$\mathrm{XR}$ refers to all real-and-virtual combined environments and multimodal interactions generated by computer technology and wearables. It includes representative forms such as virtual reality (VR), augmented reality (AR), and the areas interpolated among them [8]. The level of virtuality range from partially to fully immersive is defined by the sense of engagement through sensory channels via inputs/outputs devices such as stereoscope headsets and tracking devices. The immersive 
technologies facilitate the reality extension and transformation across the physical world and digital worlds. It has continued to evolve in rapid pace with latest technological breakthroughs and new devices for Virtual Reality (VR), Augmented Reality (AR) and Mixed Reality (MR) for the last decade. VR that immerses the user in a virtual context, AR that overlaps digital content to the real environment, and Mixed Reality (MR), that builds interactions between real and virtual worlds are the main immersive experiences developed so far [9]. The recent progress in mobile technologies has further shifted conventional desktop VR projects to portable versions with innovative and affordable headsets such as Samsung Gear VR and the Google Cardboard/Daydream headsets. AR also continues to evolve with creative projects of Microsoft HoloLens, Google's ARCore and Apple's ARKit platforms.

The educational applications of XR technologies show promising results in student centered active learning at different levels [10]. XR has critical implications for TEL research by fostering creativity which stimulates the learner's curiosity and motivation in vibrant learning environments. Transforming the way learning content is delivered, XR can be used in education to enhance student learning and engagement [11]. The immersive technologies behind extended reality (XR) are having a profound impact on TEL, supporting creativity, visual communication, and emotional reaction. Furthermore, the boundary between education and entertainment has become blurred in learning through play and personal learning focus in pervasive learning. Carrozzino and Bergamasco (2014) propose the implementation of VR in museums to enhance visitors' engagement and experience, while in a metaanalysis by Merchant et al. (2014) games show higher learning gains than simulations and virtual worlds [12][13]. With the shared core principles of immersion, interaction, and user involvement with the environment and narrative, the convergence of these developments as XR has surged to extend learning opportunities and step into the new frontier of learning era.

\section{PROJECT DEVELOPMENT: THE AGILE WORKING PROCESS}

Alexandra Palace has a prestigious place in British cultural heritage. It opened as 'The People's Palace' in 1873 and now attracts more than 1 million visitors to exhibitions and events each year. It has become a vibrant learning hub to support communities via public engagement. Their educational and interpretation strategies aim:

- To shape Alexandra Palace's identity by promoting its history, functions and audiences

- To raise the cultural capital by positioning content to cultivate diverse visitors' expectations

- To deliver layers of content pitched at different levels and formats to be as inclusive as possible

- To explore digital inclusion by developing academic partnerships for future aspirations

- To sustain heritage content via strategic co-creation to build stronger networks of support

Through analysing the AP interpretation strategy, the pilot collaboration prioritises positioning AP to assume a leading role in the cultural sector, with demonstrations of rapid and adaptive application of novel digital technology within a heritage and educational context. To achieve this, the agile method was introduced in the working process in project development and management. The Agile working processes have recently taken hold across the creative industries for digital transformation [14][15]. The agile working process refers to an iterative, incremental method of managing design and development that aims to provide digital solutions or services in a highly flexible and interactive manner. The method highlights four values:

- Individuals and interactions over processes and tools

- Working prototype over comprehensive documentation

- Collaboration and communication over negotiation

- Interaction responding to change over following a frozen plan

In principle, we treat students as co-creators in the collaboration through a series of student engagement workshops. Intensive network meetings and field trips advanced mutual understanding through interactions and communication. For example, we had field trips to the National Science and Media Museum at Bradford, UK where we investigated the AP's historical assets and collections for content digitization shown in Figure 2. The Agile working process helps the shortness of an iteration and new features can be efficiently added into the next iteration. Through iterations, we identified the potential benefits in creating a symbiotic relationship between collaborative partners to allow students using the content and heritage assets from AP archive to inspire creativity. The partnership offers the 
opportunity to solve some of the real-world problems in cultural sectors that include providing relevant and engaging experiences for young audiences; the difficulty of 'bringing history to life', promoting lowcost repeat visits; and stimulating curiosity about personalities and stories.

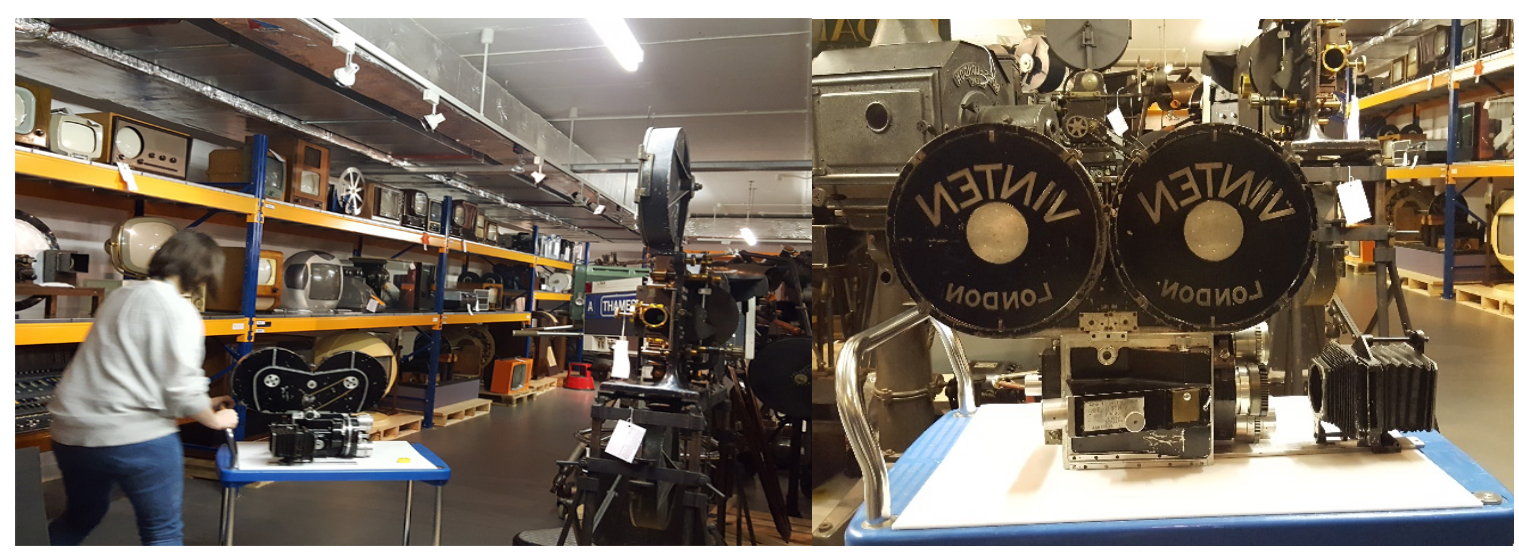

Figure 2. The study of cultural assets in agile working process.

\section{PROJECT OUTCOMES AND DISCUSSIONS}

By conceptualizing the agile transformation process through our technoself theory recommended in section 2, we employed TEL approach with XR technology to foster creativity in the collaborative learning and interpretation practices. As a result, we successfully designed and prototyped two pilot creative interpretation apps, that recreate the historic scenarios and collections at AP. Students were actively engaged in the project to work on the digital solutions that promote unforgettable stories. These included 'Step Back in Time', a mobile VR interactive tour of historic spaces that takes visitors back to the Victorian period; and 'Digital 3D Popping up', a mobile interactive AR application showcasing 3D historical equipment from the $1936 \mathrm{BBC}$ television studio at AP.

\subsection{Increasing Accessibility via Immersive Experience: Step Back in Time}

Alexandra Palace is known globally as the birthplace of the BBC television service. In November 1936 the British Broadcasting Corporation launched the first public television transmissions from broadcast studios at the eastern wing of the Palace. Through decades of pioneering work, teams of producers, performers and engineers built the powerful medium we know today. However, after its closure in 1980 , the studios became derelict and the historic spaces were not accessible to the public. AP is keen on seeking alternative means of access to the historic heritage site for public engagement. According to a survey of scientific literature on the advantages and potential use of Immersive VR in Education [16], it shows how immersive VR has been used mostly for learning in special situations like recreation via simulation. It focuses on the possible advantages and drawbacks of its use in education with reference to diverse audiences like youth and even cognitive disabilities. Based on the literature review, we designed a VR solution to increase the accessibility of the iconic 1936 BBC Studio B and to reveal its historic stories. As a project outcome, a mobile VR interactive tour app was prototyped to let visitors step back in time to explore this space. The technical solution uses a popular modern game engine, Unreal Game Engine 4 to develop an interactive game-like scenario bringing visitors to experience a guided tour of the Victorian dining rooms as shown in Figure 3 and as transformed into BBC studios in 1936, by following a controllable interactive timeline. Up to now, most VR educational apps e.g. games have been limited due to expensive and heavy devices e.g. HTC VIVE and the side effects in terms of usability e.g. VR cybersickness during immersion [17][18]. To alleviate negative aspects, we adopted affordable portable VR headsets (e.g. Google Cardboard and Samsung Gear $\mathrm{VR}$ ), which allow as wide a range of audiences as possible to achieve immersive experience. Consequently, the VR prototype as shown in Figure 3 facilitates immersion, interaction, and user involvement within simulated scenarios while weaving narrative together. This approach to the interpretational journey through historic spaces offers a very high potential in making learning a more motivating and engaging voyage of discovery. 


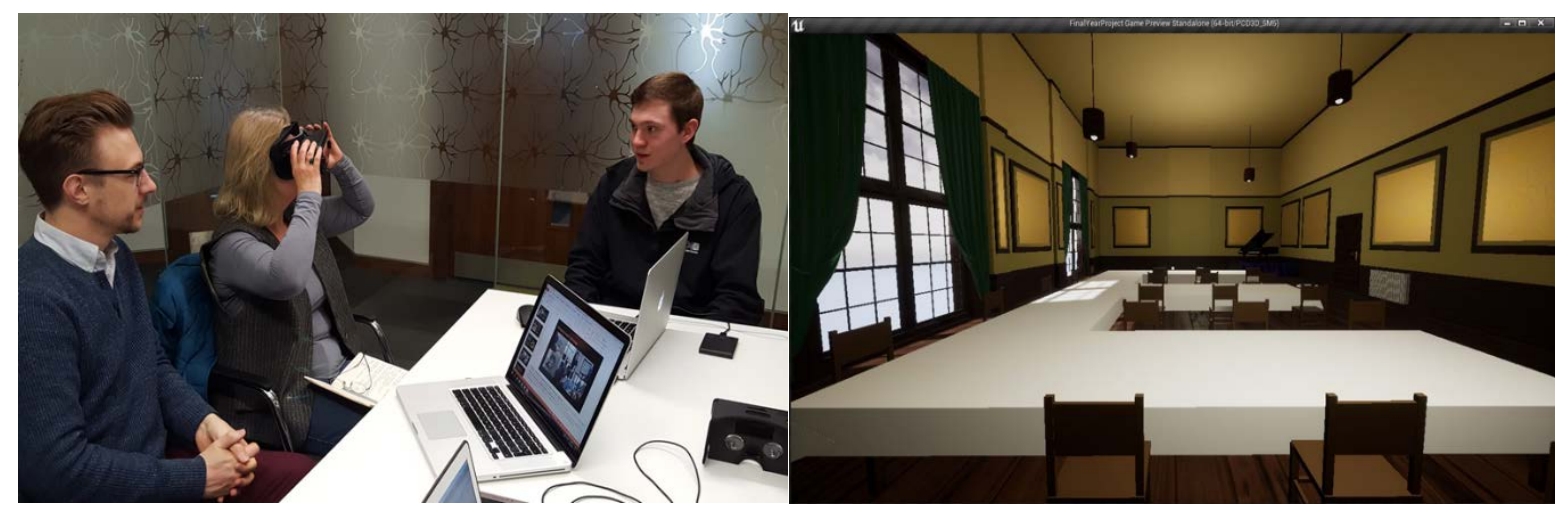

Figure 3. The VR interpretation prototype - 'Step Back in Time’

\subsection{Showcasing Cultural Assets in a Creative Way: Digital 3D Popping up}

In 1936 the BBC erected a huge transmitter and installed two television studios at AP that housed rival systems for broadcasting television: Marconi-EMI in Studio A, Baird Television Ltd in Studio B. The BBC alternated between these two systems for broadcasting the opening ceremony.

Cultural assets representing this period of experimentation and competition include the EMI Emitron camera and the Vinten Model H 35mm camera, used in the Baird system [19]. However, none of the $\mathrm{BBC}$ equipment was kept at $\mathrm{AP}$ and iconic objects were discretely kept in different UK national museums. Figure 2 and Figure 4 show a Vinten camera and original Emitron camera from the collections of the National Science and Media Museum at Bradford, UK. Without access to BBC cultural assets of this type, there exists a significant challenge for AP to attract diverse visitors and meet their expectations in today's highly competitive cultual sector.

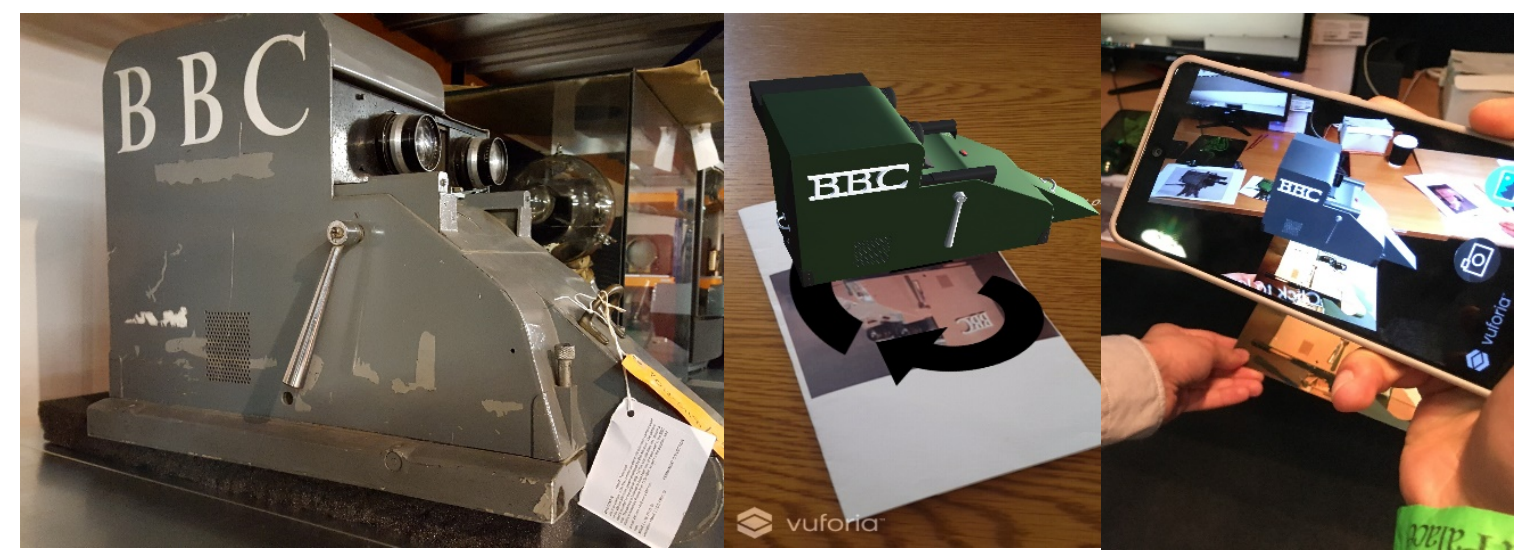

Figure 4. The AR showcasing prototype - 'Digital 3D popping up'

Research has so far highlighted $A R$, which can bring a new level of immersion into the creative learning environment to adapt to the needs and inputs from learners [20]. We then proposed an AR solution to showcase cultural assets in digital ways by delivering layers of content pitched at different levels and formats. To validate this approach, a mobile interactive AR app was developed to showcase historic equipment originally used in the BBC studios at AP (e.g. Emitron camera) within a real surrounding environment to achieve hybrid interactive experience. The technical solution uses Vuforia AR SDK to track 2D images/photos of selected collections as markers to popup 3D models of equipment. It was developed to allow the audience to have a full 3D view of these collections with its state and profile information in the past, by encoding context-dependent information associated with the collection item. The project also tried to address issues on how effective semantic transitions can be achieved in a user-friendly way and how the user can intuitively manipulate objects. As shown in Figure 4, the AR-based learning system successfully superimposes a 3D model of the Emitron camera with other guidance information into the real context by using a simple 2D postcard image. 


\subsection{Validations and Discussions}

Furthermore, we led students to take part in 'The Great Fete' summer festival at Alexandra Palace to demonstrate these prototyped creative learning and interpretation solutions in the 'New Tech for Old Stories' showcase on 18 August 2018. Attendance at the festival was around 10,000 Londoners over 250 of them interacted with students from UOW in this outreach activities in the promotion of the project outcomes to visitors of different age groups, from schools and local communities. As shown in Figure 5, children got so excited seeing an Emitron camera hovering above the desk or table like the holograms in science fiction movies and even a toddler enjoyed the 'Step Back in Time' virtual tour of AP. These visitors' positive reaction and collective feedback provide strong evidences that the technoself enhanced learning with XR has successfully transferred the entire learning process in a fun and exciting way.

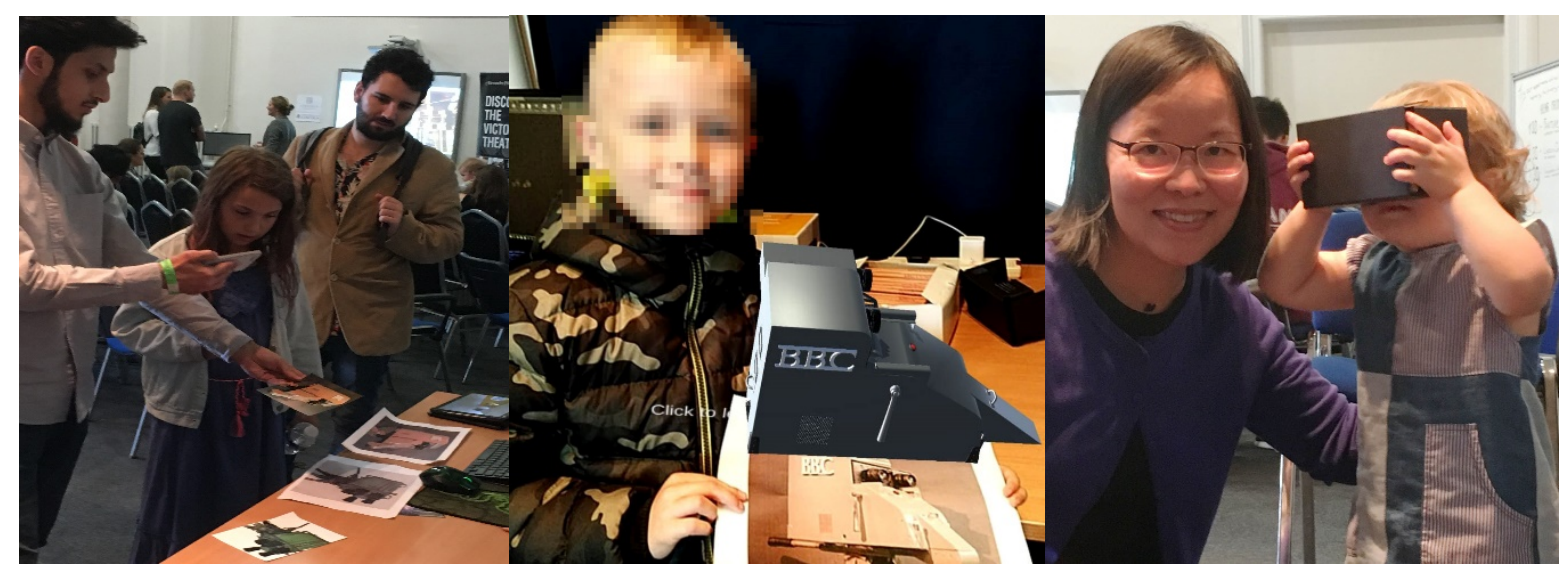

Figure 5. The demonstrations of project outcomes at AP Summer Fete 2018.

Thanks to the latest technical innovations, XR functions by enhancing one's current perception of reality and further affects one's perceived behavioural control in the technoself system presented in Section 2. By adopting XR in TEL, it opens new opportunities to increase the learner's engagement and gain greater understanding in a creative way. It helps learners hear, see and feel their surroundings in new ways, which enables various degrees of immersion in a vibrant learning environment. Immersion is the subjective impression that one is participating in a comprehensive, realistic experience. The more a virtual immersive experience is based on design strategies that combine actional, symbolic, and sensory factors, the greater the participant's suspension of disbelief that she or he is "inside" a digitally enhanced setting. These prototypes allow users to control their own learning pace, through active interactions within the hybrid learning environment. Consequently, the project outcomes link directly to the AP interpretation strategy and help deliver some of the public engagement strategic objectives for the Charitable Trust.

\section{CONCLUSIONS AND FUTURE WORK}

In this paper, we presented the research methodology of a technoself enhanced approach for fostering creativity. We treat students as co-creators to get involved in external projects and further transform their knowledge and skills by exploring digital transformation approaches to cultural communication. By adopting the emerging XR technology, the technoself enhanced learning suggests a learner-centric solution to creative learning. We then analyzed the cultural sector interpretation strategy on how to connect with learners and further create new ways to engage, and introduced the agile working process in the project development. Finally, we applied the technoself enhanced learning approach to enhancing the learner's motivation and engagement and successfully prototyped two pilot creative learning and interpretation apps, that recreates the historic BBC Studios at AP. By incorporating mobiles, gaming, eye gaze, and multimodal interaction through $\mathrm{XR}$ in creative learning, the 'technoself' plays a major role in how learners perceive learning settings and how they behave in response to different learning setting and situations. The project outcomes were showcased in the 'New Tech for Old Stories' exhibition at Alexandra Palace to evaluate these pilot creative learning and interpretation solutions through public engagement. The collective feedback received shows the pedagogic approach has fostered a vibrant learning environment that supports learners' diversity and individual needs. This diversity can include learner differences in prior knowledge, competencies, 
learning style, communication preferences, cognitive style, and so on. In summary, the pilot collaborative learning practices developed in partnership with cultural sectors fosters innovation and creativity, inspired by TEL via student Engagement.

However, the challenges of fostering creativity and stimulating learning experiences that support learner collaboration, self-construction, and self-reflection remains key to successful in the next generation of TEL. Although XR as a frontier in TEL has bridged the virtual learning world and the physical based learning environments, there are still many barriers to its adoption in education. XR is limited by a highly fragmented system of hardware platforms and operating systems; a lack of standards for sharing data and supporting multimodal interactions; and technical barriers in optics, force feedback, content capabilities, and authoring tools, which require further technical breakthroughs. Furthermore, such emerging technologies are sometimes for the more tech-savvy learners due to the high level of novelty. These cause some research arguments on the impact of selfefficacy in TEL, which refers to one's belief in his or her ability to succeed in a particular learning situation [20][21]. In our future research, we will also examine how self-efficacy affects the technoself pedagogy with emerging XR technology. As XR evolves, artificial intelligence (AI) will become a driving force in shaping learners' immersive experiences. Al will allow XR devices to learn user behaviours and drive greater interactivity. Google's recent research in light-field camera technology could create a much more immersive environment by letting viewers look partially around objects. As this technology evolves, XR environments will be more immersive and expand creative possibilities in diverse learning situations. The growth of these technologies will change the way we think about reality and existence itself, potentially defining a shift in human experience by offering deeper and more vivid learning experiences.

In summary, the collaborative pedagogic learning practice facilitates students at the University of Westminster, UK to develop their abilities in the combination of grasping experience and transforming knowledge and further shape them as new era of learners, appreciating the need for interdisciplinary approaches in understanding TEL. It supports the Alexandra Palace Trust to inspire their visitors and to help curators think beyond their current boundaries, providing a new, mixed media and technological approach to spread the story of Alexandra Palace up to today. In the future collaborations we will explore how to meaningfully engage with cross discipline students whose farreaching interests can often have a digital transformational impact on the cultural landscape and pedagogical impact on the wider communities.

\section{ACKNOWLEDGEMENTS}

This collaboration between University of Westminster and the Alexandra Park and Palace Charitable Trust was originally facilitated by the Museum University Partnership Initiative funded by Arts Council England. Thanks to computer science students at UOW, Emre Irmak and Zaid Esmail as co-creators who developed digital apps in their Final Year Project.

\section{REFERENCES}

[1] T.C. Pannells and A.F. Claxton, "Happiness, creative ideation, and locus of control," Creativity Research Journal, vol.20, no. 1, pp.67-71, 2008.

[2] M. L. S. Alencar, Eunice \& Fleith, Denise \& Pereira, Nielsen, "Creativity in Higher Education: Challenges and Facilitating Factors," Trends in Psychology, vol. 25, no.2, pp.553-561, 2017.

[3] R. Luppicini, "The Emerging Field of Technoself Studies" in Handbook of Research on Technoself: Identity in a Technological Society, pp. 1-25, Hershey, 2013

[4] L. Jin, "A New Trend in Education: Technoself Enhanced Social Learning" in Handbook of Research of Technoself: Identity in a Technological Society, pp. $456-473$, IGI Global Publishing, 2012.

[5] A. Bandura, Social Learning Theory, New Jersey: Prentice Hall, 1977.

[6] F.D. Davis, "Perceived usefulness, perceived ease of use and user acceptance of information technology," MIS Quarterly, vol.13, no. 3, pp 319-339, 1989.

[7] L. Jin, W. Huang, and Z. Wen, "Developing a Technoself System to Improve Lifelong Learning Engagement," Proceedings of IEEE International Conference on Teaching, Assessment, and Learning for Engineering, 10-12th Dec. Zhuhai 2015. 
[8] A. Storchi, Extended Realities: Insights from the next generation's technology, 2018. Retrieved from https://www.researchgate.net/publication/329181085_Extended_Realities_Insights_from_ the_next_generation's_technology

[9] N. Kunkel and S. Soechtig, Mixed reality: Experiences get more intuitive, immersive, and empowering, Deloitte Insights, 2017. Retrieved from https://www2.deloitte.com/insights/us/en/ focus/tech-trends/2017/mixed-reality-applications-potential.html

[10] J. Bacca, S. Baldiris, R. Fabregat, S. Graf, and Kinshuk, "Augmented Reality Trends in Education: A Systematic Review of Research and Applications," Educational Technology \& Society, vol.17, no.4, pp.133-149, 2014.

[11] N. Babich, How Virtual Reality Will Change How We Learn and How We Teach, 2018. Retrieved from https://theblog.adobe.com/virtual-reality-will-change-learn-teach/

[12] M. Carrozzino and M. Bergamasco, "Beyond virtual museums: Experiencing immersive virtual reality in real museums," Journal of Cultural Heritage, vol. 11, no.4, pp.452-458, 2010.

[13] Z. Merchant, E.T. Goetz, L. Cifuentes, W. Keeney-Kennicutt, and T.J. Davis, "Effectiveness of virtual reality-based instruction on students' learning outcomes in K-12 and higher education: A meta-analysis," Computers \& Education, vol. 70, pp. 29-40, 2014.

[14] C. Fuchs and T. Hess, "Becoming Agile in the Digital Transformation: The Process of a LargeScale Agile Transformation," in Proceedings of the 39th International Conference on Information Systems (ICIS 2018), 2018. At San Francisco, USA Dec. 2018.

[15] D. K. Rigby, J. Sutherland and H. Takeuchi, "Embracing Agile - How to Master the Process that's Transforming Management," Harvard Business Review, vol. 94, no. 5, pp. 41-50, 2016.

[16] L. Freina and M. Ott, "A Literature Review on Immersive Virtual Reality in Education: State Of The Art and Perspectives" in Conference: eLearning and Software for Education (eLSE), 2015. At Bucharest (Romania), 2015.

[17] S. Zaidi and T. Male, "Experimenting novel virtual-reality immersion strategy to alleviate cybersickness," in Proceeding of VRST '18 Proceedings of the 24th ACM Symposium on Virtual Reality Software and Technology, 2018. No.89, Tokyo, Japan, Nov. 28 - Dec.01, 2018.

[18] D. Lu. Virtual Reality sickness during immersion: An investigation of potential obstacles towards general accessibility of VR technology, 2016. Retrieved from http://www.divaportal.org/smash/record.jsf?pid=diva2\%3A1129675\&dswid=8500

[19] Elinor Groom, 80 years ago today, Alexandra Palace became the birthplace of British television as we know it, 2 November 2016. Retrieved from https://blog.scienceandmediamuseum.org.uk/80years-ago-the-opening-of-the-british-television-service/

[20] Y. Joo, M. Bong and H. Choi, "Self-efficacy for self-regulated learning, academic self-efficacy, and internet self-efficacy in web-based instruction," Educational Technology Research and Development, vol.48, pp.5-17, 2000.

[21] M. Sırakaya and E. Cakmak, "Effects of Augmented Reality on Student Achievement and SelfEfficacy in Vocational Education and Training," International Journal for Research in Vocational Education and Training, vol. 5, no. 1, 2018. 